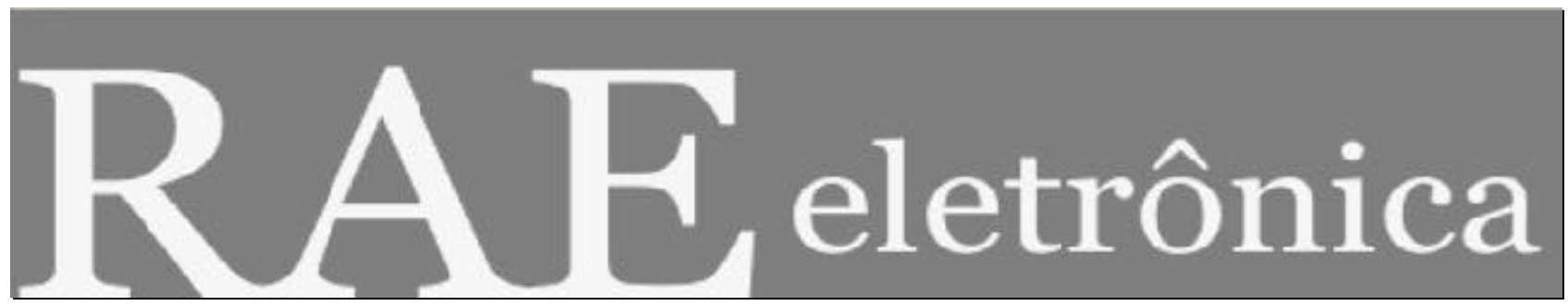

\title{
SOFT SYSTEMS METHODOLOGY: UMA APLICAÇÃO NO "PÃO DOS POBRES" DE PORTO ALEGRE
}

\author{
Por:

\section{Carlo Gabriel Porto Bellini \\ Ionara Rech \\ Denis Borenstein}

RAE-eletrônica, v. 3, n. 1, Art. 3, jan./jun. 2004

http://www.rae.com.br/eletronica/index.cfm?FuseAction=Artigo\&ID=1790\&Secao=INFORMAÇÃO \& Volume $=3 \&$ Numero $=1 \& A$ no $=2004$

CCopyright, 2004, RAE-eletrônica. Todos os direitos, inclusive de tradução, são reservados. É permitido citar parte de artigos sem autorização prévia desde que seja identificada a fonte. A reprod ução total de artigos é proibida. Os artigos só devem ser usados para uso pessoal e nãocomercial. Em caso de dúvidas, consulte a redação: redacao@ rae.com.br.

A RAE-eletrônica é a revista on- line da FGV-EAESP, totalmente aberta e criada com o objetivo de agilizar a veiculação de trabalhos inéditos. Lançada em janeiro de 2002, com perfil acadêmico, é dedicada a professores, pesquisadores e estudantes. Para mais informações consulte o site www.rae.com.br/eletronica.

RAE-eletrônica

ISSN 1676-5648

(C2004 Editora: Fundação Getulio Vargas - Escola de Administração de Empresas de São Paulo

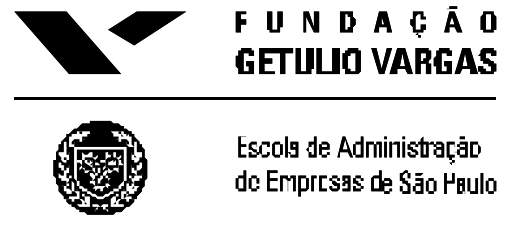




\title{
SOFT SYSTEMS METHODOLOGY: UMA APLICAÇÃO NO "PÃO DOS POBRES" DE PORTO ALEGRE
}

\section{RESUMO}

O artigo apresenta uma aplicação da Soft Systems Methodology (SSM) na entidade filantrópica portoalegrense Pão dos Pobres de Santo Antônio, que presta assistência a meninos carentes. Busca-se divulgar no contexto nacional a SSM como metodologia para o tratamento de problemas complexos, bem como incentivar a interação de acadêmicos e empresários com setores comunitários especialmente necessitados. A aplicação da SSM resultou positiva para a entidade e para os pesquisadores: permitiu se estabelecer uma visão global e sistêmica da realidade do Pão dos Pobres, sugeriu alternativas para o enfrentamento de situações problemáticas nela identificadas, serviu de meio para os autores conhecerem aspectos da vida comunitária e promoveu cooperação e aprendizagem entre as pessoas envolvidas no estudo - um dos benefícios mais documentados na literatura como resultantes da aplicação da metodologia.

\begin{abstract}
The paper introduces an application of the Soft Systems Methodology (SSM) in the charity organization Pão dos Pobres de Santo Antônio, located in Porto Alegre, Brazil, which assists boys living under intensive social privation. The aim is to divulge for the Brazilian audience a methodology for studying complex settings, and to foster the interaction of academicians and practitioners with community groups facing special needs. Implementing the SSM was interesting for both organization and researchers: it supported a global and systemic understanding about the charity to mature, suggested alternatives for dealing with issues in it, granted the authors access to blurred facets of their community, and nourished cooperation and learning of all stakeholders - notably one of the most reported benefits as resulting from the methodology.
\end{abstract}

\section{PALAVRAS-CHAVE}

Soft Systems Methodology, sistemas complexos, pensamento sistêmico, aprendizagem, filantropia.

\section{KEY-WORDS}

Soft Systems Methodology, complex systems, systems thinking, learning, philanthropy. 


\section{INTRODUÇÃO}

A dificuldade, sobretudo financeira, por que passam as instituições filantrópicas e de caridade tradicionais no Brasil é paradoxal se comparada aos muitos casos de sucesso de ONGs no país. A inadequação, porém, de se transformar algumas delas em empreendimentos de negócio - o que poderia ser imaginado como uma primeira solução para o problema - implica a necessidade de se realizar uma avaliação de seus aspectos gerenciais para torná-las auto-sustentáveis.

As constantes dificuldades enfrentadas pela instituição Pão dos Pobres de Santo Antônio, que há mais de um século presta assistência a meninos carentes na cidade brasileira de Porto Alegre, são parte deste contexto. O Pão dos Pobres enfrenta seguidas crises econômicas de causas externas (como a diminuição do poder aquisitivo da população) e internas (como problemas de gerenciamento comuns a qualquer entidade filantrópica em que a administração ainda não se profissionalizou completamente), e, a partir deste quadro, quis-se aplicar uma metodologia sistêmica de diagnóstico da referida entidade e oferecer aos seus gestores opções para a melhoria de processos. Viu-se a possibilidade de se realizar, sem custo financeiro para o Pão dos Pobres, um mapeamento de pontos críticos em alguns de seus processos administrativos e operacionais e sugerir correspondentes alternativas viáveis de tratamento; simultaneamente, o meio acadêmico poderia, por meio do estudo proposto, estreitar os laços com a comunidade e ter contato com a prática administrativa em setor tão peculiar quanto o da filantropia.

$\mathrm{Na}$ avaliação de uma organização, deve-se levar em conta as percepções daqueles que trabalham no seu dia-a-dia e que estão envolvidos com suas deficiências e qualidades. É comum, entretanto, realizaremse avaliações com a simples contratação de serviços externos de consultoria, sem que haja qualquer envolvimento dos funcionários. Obtêm-se, assim, soluções muitas vezes extrínsecas ou pré-formatadas, as quais não respeitam a cultura da organização e impedem a efetiva implementação de propostas de melhoria. Diferentemente dessa prática usual, o presente artigo demonstra o uso de um método sistêmico para avaliação de uma organização - o Pão dos Pobres -, avaliação esta realizada por membros seus e pessoas a ela vinculadas, e cabendo aos analistas externos - os autores - o papel de facilitadores do processo.

A Soft Systems Methodology (SSM) foi selecionada como metodologia de trabalho por sua capacidade de lidar com situações bastante complexas, onde não existe consenso acerca do problema; ou seja, são conhecidas as consequiências mas não se sabe exatamente o que fazer para que o sistema em foco atinja seus objetivos - e este é o caso preciso da realidade do Pão dos Pobres. Além disso, a SSM está consolidada em círculos acadêmicos como a mais desenvolvida abordagem soft e um importante veículo para pesquisa-ação (Rose, 1997). Utilizada em conjunto com conceitos clássicos da Teoria Geral de Sistemas, ela apresenta um excelente suporte para a expressão formal de cenários problemáticos, assim como da concepção mental das pessoas sobre o ambiente em que operam. Desta forma, são produzidos diagnósticos sob consenso, em função da capacidade de cada pessoa em identificar e expressar sua visão de mundo em um processo de complementação de visões individuais.

O artigo que ora se apresenta está organizado da seguinte maneira: primeiro, realiza-se uma revisão bibliográfica sobre a SSM, com destaque para os seus sete estágios de aplicação, exemplos de casos e limitações; em seguida, caracteriza-se o Pão dos Pobres como situação problemática a ser investigada; posteriormente, aplica-se a SSM ao Pão dos Pobres, propondo-se um conjunto de ações exeqüíveis para o tratamento de temas de central interesse para a entidade; e, por fim, procede-se a considerações finais sobre o trabalho realizado, enfatizando-se benefícios e limitações. 


\section{SOFT SYSTEMS METHODOLOGY}

A Soft Systems Methodology (SSM), metodologia - e não técnica (Flood e Carson, 1988) - proposta por Peter Checkland (1981) para a articulação de problemas pouco estruturados, foi a abordagem sistêmica adotada no trabalho. Entre os motivos para esta escolha, destaca-se a sua proeminência na literatura acadêmica sobre realidades complexas (Ranyard, 2000; Rose, 1997). A sua aplicação se fundamenta em uma ampla interação entre facilitadores e pessoas envolvidas nas situações em estudo, pois o que se busca é o aprendizado (Checkland, 1999; Flood e Carson, 1988) e a acomodação de múltiplos interesses (Wheeler, 2000) e visões (Patching, 1992). De fato, ela objetiva o consenso a partir da participação de pessoas de todos os níveis organizacionais (Patching, 1992). A SSM, portanto, tem uma base fenomenológica (Mingers, 2000), e isto está de acordo (cf. Williams e Dickson, 2000) com proposições correntes no campo da pesquisa operacional.

Nas ciências sociais, a SSM é uma metodologia de gestão (Rose, 1997) essencial para qualquer planejamento (Patching, 1992), focando os seguintes aspectos:

- exame das percepções do mundo real;

- definição de ações para se atuar no mundo real; e

- reflexões sobre os efeitos resultantes das ações tomadas.

Como metodologia soft (Checkland, 1985a; Jackson, 1999; Flood e Carson, 1988), a SSM não produz respostas finais a questionamentos (Checkland, 1985a) nem acompanha o pesquisador durante as implementações (Ranyard, 2000), mas o remete, muitas vezes, a abordagens hard para esses fins (Checkland, 1999) - uma comparação entre as abordagens hard e soft pode ser conferida em Jackson (1999). Isto está de acordo com o entendimento de que a SSM não é prescritiva (Patching, 1992) e propõe questões a serem tratadas por outros meios (Rose, 1997). O questionamento, então, na SSM, é algo que nunca termina (Checkland, 1985a).

Checkland (1981) indica sete estágios para a aplicação da SSM (Figura 1), enfatizando suas características de apoio à aprendizagem e à reformulação de hipóteses. Neste sentido, os aplicadores da SSM devem (conforme método e terminologia a serem discutidos na próxima seção): (1) explorar uma situação problemática não estruturada, (2) expressá-la, (3) construir definições sucintas de sistemas relevantes, (4) elaborar modelos conceituais desses sistemas, (5) comparar os modelos com a situação problemática expressada, (6) reunir mudanças culturalmente possíveis e sistemicamente desejáveis, e (7) sugerir ações para transformação da situação problemática. 


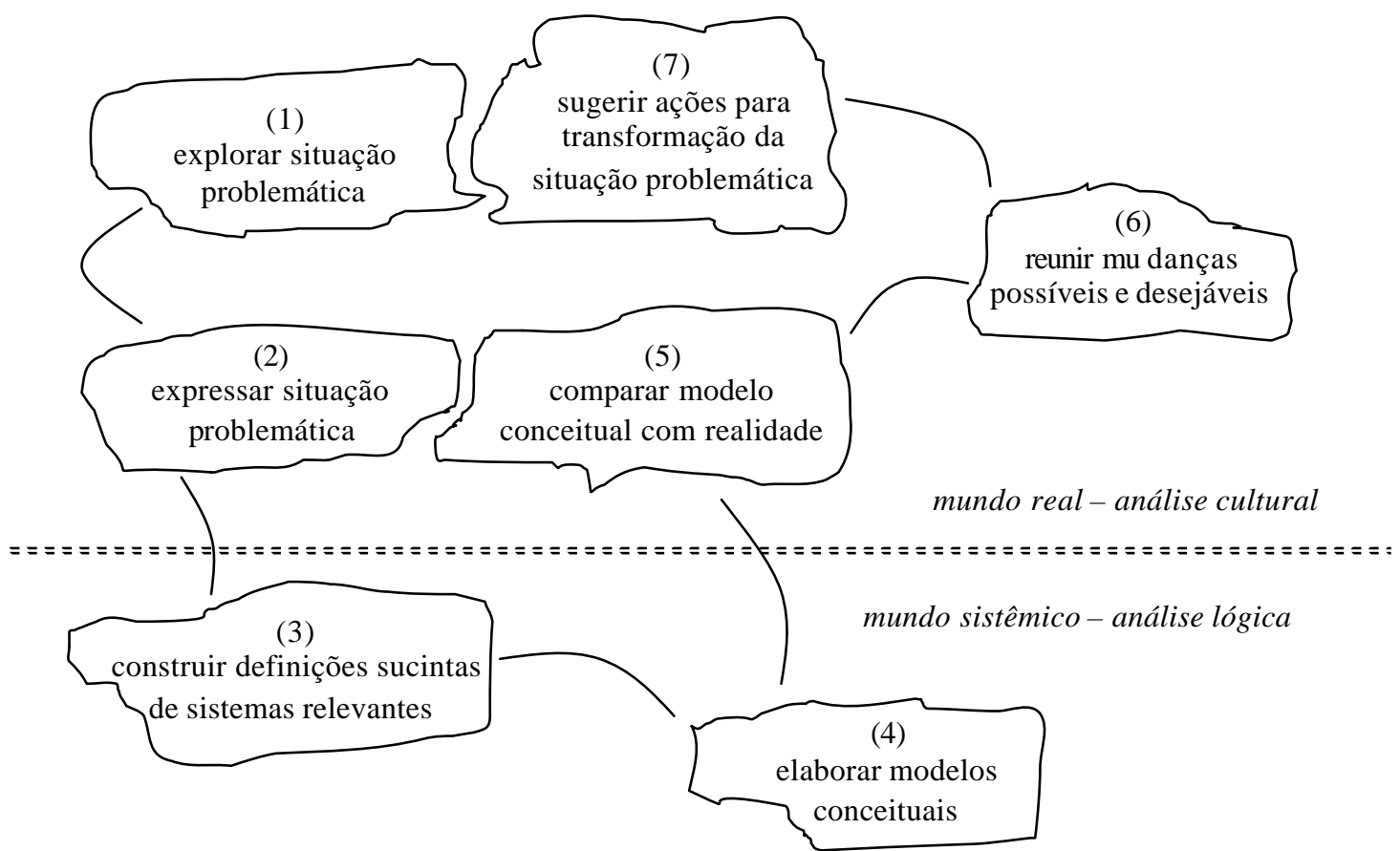

Figura 1. Estágios da Soft Systems Methodology. Fonte: Checkland (1985b)

\section{Domínios de Aplicação, Benefícios e Limitações}

A literatura não aprofunda a discussão sobre os casos em que a SSM é de aplicação mais recomendada, apenas enfatizando a sua conveniência para situações sociais complexas, em que a mensuração e o controle são impraticáveis ou ineficientes. Talvez o pouco debate em torno das possíveis aplicações da SSM seja devido ao entendimento de alguns de que ela pode servir a qualquer situação problemática (Gregory e Lau, 1999), contexto organizacional (Patching, 1992) ou pesquisa social aplicada (Rose, 1997) e que sua eficácia raramente é afetada por culturas internas ou estilos gerenciais (Patching, 1992). Ainda assim, Rose (1997) especifica algumas áreas de uso potencial, entre as quais estão a indústria, o setor público e as instituições de filantropia (como a do presente trabalho). Também não há boas referências sobre a duração média de uma aplicação da SSM, embora Gregory e Lau (1999) estimem algo em torno de seis meses.

Da mesma forma, pouco demarcada está a gama de situações em que a SSM não se mostra eficaz. Além da conclusão imediata de que ela não se presta à operacionalização de soluções, Rose (1997) destaca como impróprios ao âmbito da SSM alguns ambientes intransigentes e autocráticos, e Gregory e Lau (1999) alertam para cuidados especiais com sociedades - como algumas do Extremo Oriente que evitam o confronto de idéias (obstruindo a discussão em grupo) ou em que há alta rotatividade $\mathrm{m}$ emprego (prejudicando a implementação, pelos participantes do projeto, das propostas de solução oriundas da SSM). Também se indica que, na tomada de decisão gerencial, a SSM não pode ser usada para a previsão de efeitos de opções estratégicas (Patching, 1992).

Revisando-se a literatura sobre aplicações da SSM, verifica-se grande variedade de temas, áreas do conhecimento e interesses práticos em que se empregou a metodologia. Exemplos incluem o uso da 


\section{GESTÃO DA INFORMAÇÃO -SOFT SYSTEMS METHODOLOGY: UMA APLICAÇÃO NO \\ "PÃO DOS POBRES" DE PORTO ALEGRE \\ Carlo Gabriel Porto Bellini - Ionara Rech - Denis Borenstein}

SSM na análise organizacional interna de departamento de serviços sociais para a formulação de estratégias (Patching, 1992), no desenvolvimento de sistema de apoio a decisões (Binyusoff e Jenkins, 1994) e na análise do trabalho em indústria de laticínios (Reid et al., 1999); uma versão da SSM foi empregada na identificação de informações necessárias para o apoio a decisões de departamento de marketing de empresa de telecomunicações (Gregory e Lau, 1999), bem como se fez uso conjunto da SSM e da teoria da estruturação no desenvolvimento de sistemas de informação (Rose, 2000; Rose, 2002) e uso da SSM e da dinâmica de sistemas na análise do tráfico de drogas (Coyle e Alexander, 1997). Destaca-se que a SSM também deu origem a outras metodologias (e. g., Atkinson, 2000).

Independente da aplicação específica da metodologia, seu principal resultado é o aprendizado (Checkland, 1999; Flood e Carson, 1988; Rose, 1997). Em essência, a SSM favorece o pensamento sistêmico e organiza uma agenda para se discutirem problemas e soluções (Patching, 1992), mas não produz respostas finais (Checkland, 1985a) ou resultados fixos (Gregory e Lau, 1999). Os benefícios da sua aplicação advêm do processo como um todo, destacando-se os seguintes (cf. Patching, 1992):

- encoraja-se o analista a considerar questões e temas problemáticos (em vez de problemas específicos);

- promove-se um melhor entendimento acerca de fraquezas organizacionais, e, às vezes, revela-se o porquê de problemas;

- não se impõem soluções tecnológicas ou modismos; e

- exige-se a participação de envolvidos na situação problemática, evitando-se a formulação de políticas alheias à realidade organizacional.

Adicionalmente, há que se citar que o debate aberto entre os principais atores de uma situação problemática estimula uma "posse" conjunta das soluções elaboradas (Patching, 1992) e essas pertencem às pessoas da própria organização (Gregory e Lau, 1999).

Em que pese, porém, a legitimidade da SSM para a administração tenha sido demonstrada em diversos trabalhos (Wheeler, 2000), a SSM não está isenta de críticas (cf. Gregory e Lau, 1999). Entre elas, Mingers (2000) e Clarke e Lehaney (2000) argumentam sobre um possível demasiado relativismo e falta de autocrítica, enquanto Gregory e Lau (1999) revelam haver duas questões comuns a boa parte do ceticismo da literatura frente à SSM: o quanto ela pode alterar uma realidade e o quão única (diferenciada) ela é para o alcance dos resultados a que se propõe.

A seguir, detalham-se os sete estágios de aplicação da SSM.

\section{Estágios 1 e 2: Situação Problemática Não Estruturada e Expressada}

Nos dois primeiros estágios, realiza-se um mapeamento da situação problemática, da maneira mais neutra possível. Para tanto, sugere-se que todas as pessoas envolvidas na modelagem (pesquisadores e envolvidos diretos com a situação problemática) elaborem figuras ricas (a nomenclatura é própria da SSM), que são representações gráficas livres com o objetivo de serem evidenciados os entendimentos individuais a respeito de problemas. O uso de gráficos encoraja a formação de idéias e facilita a observação de relações e conflitos, mas não há figuras ricas ou convenções gráficas típicas ou ideais (Patching, 1992). As figuras ricas, de fato, não têm fundamento teórico ou lógica de modelagem (Rose, 1997). 
Ranyard (2000) estende a aplicabilidade de figuras ricas para qualquer investigação de pesquisa operacional. Os aspectos principais a serem considerados na construção dessas figuras são (cf. Checkland, 1981):

- a estrutura da situação: itens estáticos (como layout físico), hierarquias formais e informais e sistemas de comunicação;

- processo da situação: entendimento de como as coisas funcionam e de quem faz o quê; e

- a relação entre estrutura e processo (o "clima" da situação): cultura organizacional.

Checkland (1981) indica que cada ponto de vista dá origem a um sistema relevante (ou assim esperase que aconteça), constituindo processo que estimula "uma busca criativa por opções desejáveis" (Ranyard, 2000, p. 1348). Tais sistemas servem para entenderem se os principais aspectos contextuais.

\section{Estágio 3: Definições Sucintas de Sistemas Relevantes}

Após o desenho das figuras ricas, discussão a seu respeito e identificação de possíveis sistemas relevantes, aspectos da situação estruturada são colocados em termos sistêmicos: uma descrição básica das atividades, sobre como elas deveriam ser, a partir de um determinado ponto de vista (Pidd, 1998). Entre os sistemas relevantes identificados, escolhe-se um que tenha maior importância segundo critérios pré-estabelecidos pelas pessoas envolvidas no estudo (pesquisadores e participantes da situação em análise). Deste particular sistema, tenta-se extrair uma estrutura fundamental, a definição sucinta, que servirá de base para o seu entendimento sistêmico e para possíveis soluções aceitáveis e desejáveis para a situação problemática (Checkland, 1981).

Checkland (1981) alerta que a elaboração dessa definição sucinta pode não ser trivial para muitas pessoas. O recurso que auxilia a sua construção é conhecido pelo mnemônico CATVPA, o qual identifica os elementos básicos que nela devem estar presentes:

- cliente - vítima ou beneficiário do sistema;

- ator - protagonista das atividades;

- transformação - transformação de entradas em saídas;

- visão de mundo - contexto;

- proprietário - quem tem poder para modificar ou parar o sistema; e

- restrições ambientais - restrições do ambiente externo.

\section{Estágio 4: Modelos Conceituais}

Conforme Gregory e Lau (1999), os modelos conceituais representam o terceiro dispositivo de modelagem da SSM (os outros dois são as figuras ricas e as definições sucintas), incorporando o que um sistema deve contemplar para estar de acordo com as definições sucintas. Utilizam-se verbos relacionados a elas e procura-se mostrar uma seqüência de atividades no sistema e os seus relacionamentos, por meio de diagramas de interconexão de atividades (Pidd, 1998). Como esta fase é uma fase do pensamento sistêmico, devem ser considerados processos de monitoramento e controle, 
além de se prever que o sistema se comunique com o mundo exterior através das suas fronteiras (Pidd, 1998). Há que se ressaltar, ainda, que os modelos conceituais não são normativos (Rose, 1997) e representam estados desejáveis, não reais (Gregory e Lau, 1999).

\section{Estágio 5: Modelos Conceituais e Situação Problemática Expressada}

Neste estágio, comparam-se os modelos conceituais com o mundo real (Checkland, 1981). Pidd (1998) acrescenta a importância de serem consideradas, no momento da comparação, as ações e mudanças necessárias para a transformação da situação problemática. Conforme Checkland (1981), quatro são as formas de se efetuar a comparação:

- usando-se o modelo conceitual para apoio à investigação requerida - o modelo conceitual não é mostrado às pessoas envolvidas na situação que está sendo modelada, e o analista o utiliza como forma de facilitar o debate sobre a mudança;

- trilhando-se o modelo conceitual com seqüências de eventos passados - investigação de como os eventos teriam ocorrido se o modelo conceitual tivesse existido anteriormente, e comparação com a prática (um problema associado é a seletividade da memória das pessoas envolvidas);

- discutindo-se o modelo conceitual com os atores principais da situação (o analista necessita de tempo para explicar as características do modelo conceitual aos envolvidos); e

- sobrepondo-se modelos - comparação do modelo conceitual com a realidade, quando se identifica a presença, ou não, das atividades do modelo conceitual no mundo real.

\section{Estágios 6 e 7: Mudanças Possíveis e Desejadas e Ações para Transformação}

Nos dois últimos estágios, elaboram-se recomendações de mudança, mas a solução para uma situação problemática nem sempre pode ser obtida com metodologia soft; de fato, pode-se requerer o uso de alguma abordagem hard para isto. O principal resultado obtido pela perspectiva soft é, já dito, a aprendizagem.

De modo geral, alternativas de ação são recomendadas ao final do estudo. Também podem ser esperadas, segundo Pidd (1998), mudanças nos aspectos tratados pelas duas primeiras fases: a estrutura (forma como as pessoas são organizadas e controladas), o processo (modo como as pessoas trabalham e suas interações neste particular) e o clima (atitudes das pessoas com relação ao trabalho, clientes, etc.).

\section{PÃO DOS POBRES}

Nesta seção, apresenta-se o contexto onde se aplicou a SSM - a organização filantrópica Pão dos Pobres de Santo Antônio, de Porto Alegre. Todas as informações aqui dispostas foram estruturadas a partir de documentos e relatos de pessoas envolvidas com a organização (destacando-se o administrador geral, gerentes, beneficiários e voluntários) e refletem a realidade observada nos meses de julho e agosto de 1999.

Assim, o Pão dos Pobres foi fundado em 1895 e abrigava, originalmente, viúvas e seus filhos, mudando o foco para meninos carentes ao longo dos anos. Sua missão de "alimentar o físico, iluminar a mente, 
educar o coração e treinar as mãos" dá sentido aos diversos segmentos em que atua em favor da sociedade. Sob a administração da Cúria Metropolitana de Porto Alegre e de religiosos lassalistas, apresenta ampla estrutura, da qual serão aqui destacados o internato, a escola de Ensino Fundamental, os cursos profissionalizantes e a administração geral.

No internato, à época do estudo, atendiam-se 250 meninos carentes selecionados conforme critérios de pobreza, orfandade e saúde física e mental. Eles permanecem internos até concluírem o Ensino Fundamental e um dos cursos profissionalizantes oferecidos pela instituição. Para o seu ingresso, exige-se, ainda, terem a segunda série completa e algum vínculo familiar, no sentido de que é necessário haver um responsável pelo garoto. O motivo desta exigência é o fato de que, aos sábados, domingos, feriados e férias, os internos devem retornar às suas residências.

A realidade particular de cada garoto é extremamente diversa, inviabilizando a construção de um perfil para o menino acolhido pelo Pão dos Pobres. O caso mais raro, sim, é conhecido: dos 250 internos, apenas dois tinham pai e mãe convivendo sem maiores conflitos na mesma casa. $O$ restante era formado por meninos com pais desconhecidos, drogados, alcoólatras ou presos, irmãs prostituídas, irmãos delinqüe ntes, etc.

Por motivos assim é que o exigido retorno semanal às suas residências não representa, para todos os meninos, a melhor alternativa. No entanto, a entidade acredita ser importante para a formação dos mesmos o contato periódico com seus familiares. Mesmo que se constate o papel fundamental de educação que os internos muitas vezes exercem em seus núcleos familiares, verifica-se, também, enorme conflito cultural entre esses jovens e as pessoas de suas relações. Entre tantas razões para isto, uma delas é o fato de a instituição não ter estrutura para estender auxílio para além dos seus muros. Enquanto o jovem recebe ampla formação na entidade, alarga-se a diferença de conhecimento ético e científico com relação aos seus familiares, e a tensão respectiva não demora a surgir. Também se verifica a criação de conflito no sentido inverso: enquanto se eleva o status social do interno, este cria gostos mais refinados - como a atenção especial a determinadas marcas de roupas - e os seus familiares acabam realizando aquisições incomuns para satisfazerem o jovem exigente. A segundafeira, portanto, quando a maioria dos internos está de volta à entidade, é o dia mais tenso da semana no Pão dos Pobres, pois os garotos retornam com sintomas característicos das suas realidades pessoais, como aqueles devidos a discussões, fome, cansaço e, até mesmo, espancamento.

Casos de fumo, alcoolismo, abuso sexual e uso de drogas não são registrados na entidade, mas o roubo é problema sério. Material escolar e roupas são o alvo mais freqüente, pois os armários dos internos não têm chave e os meninos também não costumam cuidar dos seus pertences. Ainda que revistas sejam feitas, dificilmente recupera-se o objeto roubado. Usualmente, dinheiro não está envolvido nesses casos, pois, durante a semana, o mesmo fica em poder da instituição. Comportamentos rebeldes também são bastante documentados, muito disso porque, hoje, posturas mais firmes por parte dos educadores podem ser entendidas como abuso de poder, segundo leis de proteção à criança e ao adolescente - "eles têm nas mãos a cartilha com os seus direitos", relata um dos educadores. Entretanto, o número de menores que são expulsos da instituição é pequeno (em média, cinco casos por ano), o que acontece apenas após tentativas de correção de comportamento, sob a anuência dos seus responsáveis. Estes se reúnem bimestralmente na entidade, de modo a conhecerem as atividades desenvolvidas e serem mais participativos na formação dos garotos.

Uma escola de Ensino Fundamental é oferecida aos internos e a alunos particulares. Os primeiros cursam a partir da terceira série, enquanto aos últimos são oferecidas aulas desde o Jardim de Infância. Contudo, apenas a partir da sétima série os internos e os outros alunos passam a freqüentar as mesmas 
salas de aula - mudança sensível, pois haverá realidades sociais bastante diferenciadas, bem como meninos e meninas no mesmo ambiente.

Os cursos profissionalizantes são outro foco de atuação da entidade. A preocupação é preparar os jovens para o mercado de trabalho, já que suas condições financeiras dificilmente lhes viabilizariam algum curso semelhante logo após a conclusão do Ensino Fundamental. Assim, anualmente são oferecidos a 200 jovens cursos como Mecânica de Automóveis, Serralheria, Marcenaria, Tipografia e Eletricidade, cada um com duração de dois anos e 1.600 horas. Esses cursos não são exclusivos para os meninos do internato; aliás, o que se verifica atualmente é que a maioria dos alunos vem de fora da entidade. O motivo disto, por sinal, é razoavelmente simples de ser entendido: como os garotos terminam o Ensino Fundamental ao redor dos 14 ou 15 anos de idade, e nesta faixa etária (antes dos 16) a legislação impede os jovens de realizarem atividades profissionalizantes, a entidade acaba preenchendo as vagas com rapazes selecionados fora dela. E a situação se agrava porque aqueles que terminam o Ensino Fundamental e não têm 16 anos devem deixar o internato, uma vez que não existe programa para os acompanhar até serem aceitos nos cursos profissionalizantes. Aqueles, porém, que conseguirem estar dentro dos casos aceitos em lei terão acesso a material exclusivo para treinamento e estarão sob a tutela de funcionários prestadores de serviços à comunidade nas oficinas do Pão dos Pobres. Como resultado da excelê ncia dos cursos oferecidos, empresas freqüentemente selecionam mão-de-obra junto a essas oficinas.

A administração do Pão dos Pobres, assim como as suas outras divisões, enfrenta problemas variados. Além da problemática financeira (e por causa dela mesma), existe dificuldade na gestão dos recursos humanos, que são poucos e muitas vezes constituídos de voluntários. A insuficiência numérica de funcionários impossibilita, por ora, planejamentos mais tranqüilos de médio e longo prazos das atividades da instituição; ações são sempre simplificadas por serem emergenciais, e todo tipo de problema associado a isto pode aparecer.

O caso do voluntariado não é menos complexo, pois, à parte o reconhecimento do valor da pessoa que coopera sem retorno financeiro, as suas tarefas precisam ser avaliadas e cobradas com o mesmo rigor que haveria caso estivesse sendo remunerada para efetivá-las. Mas nem sempre o voluntariado reconhece tal necessidade da instituição, do que se entende que o trabalho voluntário deve ser mais bem difundido, estimulado e percebido como exercício de grande responsabilidade. Funcionários contratados e voluntários devem, então, ter um pouco das características de ambos para adicionarem valor à organização.

Apesar de comercializar produtos e serviços nas suas oficinas, na livraria e no ginásio de esportes que possui, a instituição depende fortemente de contribuições da comunidade, por não receber qualquer apoio público ou privado oficial regular. Dois aspectos relativos a alternativas para a gestão de receita e serviços assistenciais devem ser mencionados: o primeiro diz respeito ao fato de o Pão dos Pobres não ter programa específico e contínuo de marketing, de modo que qualquer campanha de arrecadação de recursos é planejada às pressas; o outro aspecto é a inexistência de programas formais de cooperação com universidades, que poderiam fornecer mão-de-obra qualificada e com acesso a modernas ferramentas de diversas áreas do conhecimento.

\section{APLICAÇÃO DA SSM NO PÃO DOS POBRES}

A aplicação da SSM aconteceu nos meses de julho e agosto de 1999 e envolveu um total de seis encontros entre os autores (facilitadores da metodologia), funcionários e voluntários da entidade e garotos por ela assistidos. 


\section{GESTÃO DA INFORMAÇÃO -SOFT SYSTEMS METHODOLOGY: UMA APLICAÇÃO NO \\ "PÃO DOS POBRES" DE PORTO ALEGRE \\ Carlo Gabriel Porto Bellini - Ionara Rech - Denis Borenstein}

Nas três primeiras visitas ao Pão dos Pobres - totalizando 6 (seis) horas de atividades -, diversas pessoas foram entrevistadas, entre funcionários, voluntários e meninos internos. Com isto, foi possível a reunião de material para se construir uma idéia dos objetivos, estruturas, processos e carências da entidade, cuja síntese se apresentou na seção anterior.

A partir dos dados coletados, os autores elaboraram, separadamente, figuras ricas, as quais foram unificadas em discussão de 2 (duas) horas entre os mesmos. A figura rica resultante foi, então, apresentada à instituição em agosto de 1999, durante 1 (uma) hora de encontro, que à figura sugeriu acréscimos. Apresenta-se a versão final da mesma na Figura 2.

Da figura rica, destaca-se o contexto do Pão do Pobres, seu funcionamento e atores. Visualizam se, por exemplo, os serviços oferecidos aos meninos do internato (atendimento de necessidades básicas, formação profissional em cursos profissionalizantes e formação moral e social) e as atividades comerciais da entidade (livraria, ginásio de esportes, escola e cursos profissionalizantes); representa-se o contexto de onde vêm os meninos (caracterizado por baixa qualidade de vida e poucas oportunidades de desenvolvimento), bem como o ambiente de que gostariam de fazer parte (onde existe progresso, conforto, carinho, etc.); os conflitos próprios da comparação de mundos tão diferentes também têm lugar na figura; e destaca-se que o lado mais favorecido da sociedade interage com a instituição por meio da contratação de serviços, doações e trabalho voluntário. Da figura, também se percebe que os meninos vêem a instituição como um caminho para o mundo idealizado, o funcionário a concebe como fonte de renda e satisfação profissional, e o voluntário a entende como meio para o avanço da sociedade.

Alerta-se para o fato de que não se adotou, a priori, qualquer convenção estilística para o desenho da figura rica - tipos de setas, linhas, tamanhos e outras formas de expressão. $O$ intuito foi se organizar livremente a percepção dos autores para uma discussão posterior sobre os principais elementos da realidade do Pão dos Pobres. Inevitavelmente, porém, a figura rica final reúne elementos convencionados pelos autores, mas cujo significado pouco enriqueceria a discussão neste artigo. 


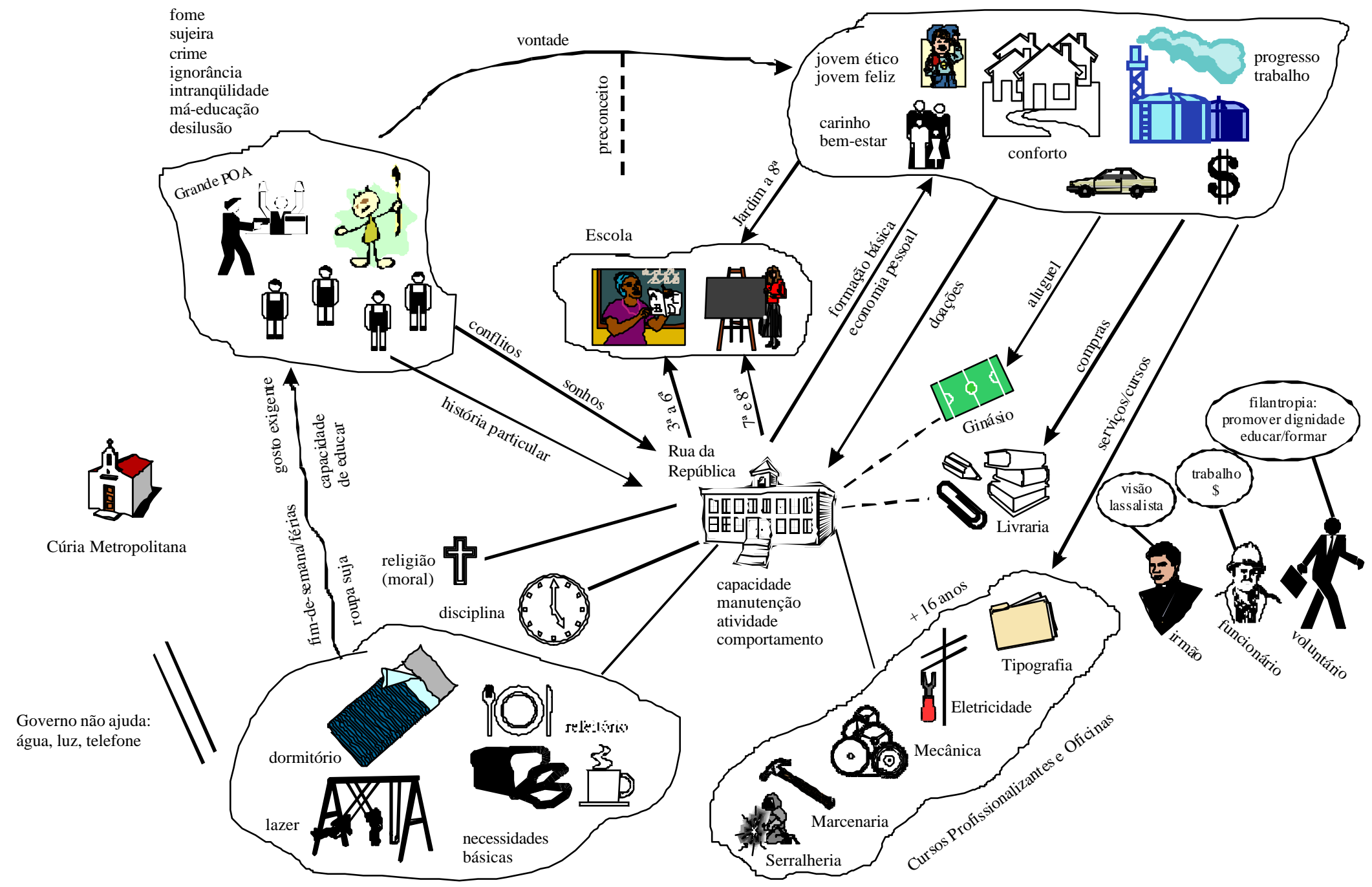

Figura 2. Figura rica. 
De posse de uma situação problemática expressada (figura rica), procedeutse à identificação de possíveis sistemas relevantes. Novamente, os facilitadores da SSM desenvolveram separadamente as suas reflexões e levaram nas ao conhecimento do Pão dos Pobres em nova visita de 1 (uma) hora de duração. De um total de cinco sistemas relevantes imaginados, dois deles foram entendidos como bastante importantes por pessoas da instituição, e um, em especial, mostroutse de extrema relevância. A seguir, apresentam-se os cinco sistemas inicialmente elaborados:

1. desenvolver programas de arrecadação de recursos financeiros, materiais e de pessoal para a manutenção da entidade em termos de estrutura física (prédios, móveis, computadores, material de escritório, etc.) e de necessidades específicas dos internos (alimentação, vestuário, material escolar e de treinamento nas oficinas, brinquedos, etc.);

2. desenvolver programas de conscientização de comportamento adequado dos internos, coibindo-se roubos e situações semelhantes;

3. acrescentar a primeira e a segunda séries do Ensino Fundamental ao currículo oferecido aos internos;

4. desenvolver programa de manutenção, na instituição, dos jovens que completam o Ensino Fundamental com menos de 16 anos; e

5. gerenciar o choque cultural entre o interno e a sua referência familiar (prover assistência social às famílias dos meninos internos, conscientizar o jovem a respeito da formação possivelmente limitada das pessoas de suas relações e a respeito das limitações financeiras das mesmas, motivá-lo a ser um disseminador de aprendizado/valores recebidos na instituição, etc.).

Dos cinco sistemas, o primeiro - relativo a programas de arrecadação de recursos - foi entendido como o de maior urgência e relevância para a entidade. Este, então, passou a ser o objeto de modelagem, expresso na seguinte definição sucinta elaborada pelos autores: "um sistema gerenciado pela Administração Geral do Pão dos Pobres e pela Cúria Metropolitana de Porto Alegre, que deve coordenar voluntários, funcionários e religiosos no planejamento e desenvolvimento eficie ntes de campanhas de arrecadação de recursos financeiros, materiais e de pessoal para a manutenção da entidade, em termos de suprimento das necessidades dos meninos internos". Esta definição está associada aos seguintes elementos:

- clientes $(\mathbf{C})$ : meninos internos;

- atores (A): funcionários, voluntários e religiosos (questões legais impedem que os internos trabalhem);

- transformação $(\mathbf{T})$ : planejamento deficiente para arrecadação de recursos vitais para a instituição transforma-se em programa bem-definido de ação neste sentido;

- visão de mundo (V): um planejamento e desenvolvimento eficiente de arrecadação de recursos vitais para a instituição é necessário para previsões de curto, médio e longo prazos;

- proprietários (P): Cúria Metropolitana de Porto Alegre e Administração Geral do Pão dos Pobres; e

- restrições ambientais $(\mathbf{A})$ : situação econômica da região, imagem da instituição junto à população e 
motivação dos atores.

Um tal sistema, centrado em uma mais efetiva visibilidade do Pão dos Pobres junto à sociedade, de modo a sensibilizá-la a transferir recursos para a instituição, constitui necessidade de organizações como universidades, bibliotecas, museus e entidades filantrópicas para ganharem suporte social, político e financeiro (O’Shaughnessy, 1996). A idéia tem claros fundamentos na teoria institucional, que sugere que a legitimidade de uma organização em seu ambiente pode ser buscada à parte do seu próprio desempenho técnico (DiMaggio e Powell, 1983).

Em função dos elementos CATVPA anteriores, imaginou-se um conjunto de ações conforme dado pela Figura 3, que representa o modelo conceitual. O modelo foi desenvolvido pelos autores e posteriormente apresentado à entidade em uma última visita de 1 (uma) hora, quando o mesmo foi aceito como identificando ações importantes para o planejamento de arrecadação de recursos para o Pão dos Pobres. Ele apresenta ações que evocam a idéia de planejamento e organização de campanhas formais de arrecadação de recursos, entre elas destacando-se as fases de concepção (com a seleção de um coordenador e priorização de necessidades, entre outras), planejamento (com a distribuição de tarefas e levantamento de alternativas possíveis, por exemplo), implementação e avaliação.

Os Quadros 1.1 e 1.2 fornecem as comparações realizadas na reunião mencionada, quando o modelo conceitual e a situação problemática vivida à época foram sobrepostos. Observou-se que algumas ações não são realizadas pelos atores no mundo real, por motivos operacionais e de percepção. Por exemplo, não se realiza a proposta de divulgação de necessidade priorizada, pois a instituição não possui uma função de marketing bem-definida - o que impede, por exemplo, a identificação do público-alvo da comunicação para divulgação de necessidades. A comunidade reconhece a marca "Pão dos Pobres", principalmente pelo seu histórico, mas a instituição ainda carece de ações voltadas à identificação dos seus simpatizantes, para que este possa, a partir de campanhas de marketing direcionadas, conhecer suas necessidades e as formas de auxiliá-la. Outras ações que não estão presentes no mundo real são o levantamento de alternativas de ação individual e a escolha daquela entendida como a melhor. $\mathrm{O}$ motivo para isto parece residir no caráter emergencial das necessidades, agregado às limitações individuais dos atores envolvidos. Como resultado, na maior parte das vezes se escolhe a alternativa que primeiro se apresenta ou a que mais facilmente pode ser implementada. Também não existe a avaliação individual formal das pessoas pelos resultados de tarefas a elas designadas, talvez por não haver critérios de desempenho validados, recursos para o seu acompanhamento e uma cultura em que o voluntário se sinta tão responsável por desempenho quanto o funcionário assalariado.

Os Quadros 1.1 e 1.2 também evidenciam ações importantes que já ocorrem na prática, mas o estudo sugere que algumas carecem de melhor estrutura operacional. 


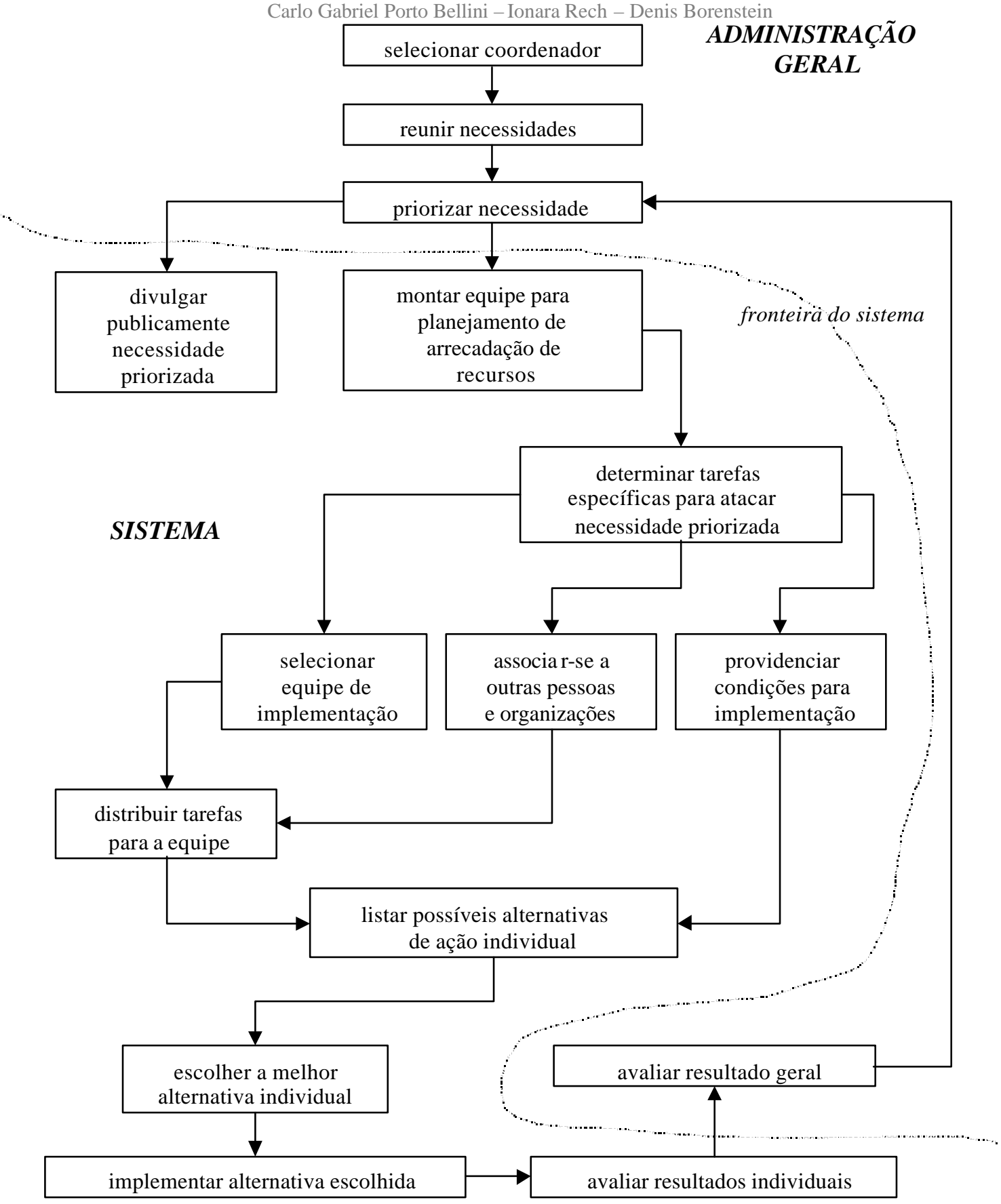

Figura 3. Modelo conceitual. 


\begin{tabular}{|c|c|c|}
\hline $\begin{array}{c}\text { MODELO } \\
\text { CONCEITUAL }\end{array}$ & $\begin{array}{l}\text { MUNDO } \\
\text { REAL }\end{array}$ & COMENTÁRIOS \\
\hline $\begin{array}{c}\text { selecionar } \\
\text { coordenador }\end{array}$ & $\operatorname{sim}$ & $\begin{array}{l}\text { A entidade tem uma coordenadora de assistência social com certa } \\
\text { autonomia para coordenar esforços de obtenção de recursos. }\end{array}$ \\
\hline $\begin{array}{c}\text { reunir } \\
\text { necessidades }\end{array}$ & $\operatorname{sim}$ & $\begin{array}{l}\text { A entidade mantém uma lista de problemas a serem resolvidos. A } \\
\text { natureza de muitas das suas atividades obriga a que tal lista seja revista } \\
\text { periodicamente, pois itens como alimentação, material de escritório e } \\
\text { pagamento de encargos necessitam de gerenciamento diário. No } \\
\text { entanto, não existe um procedimento formal de monitoramento de } \\
\text { necessidades atuais ou potenciais. }\end{array}$ \\
\hline $\begin{array}{c}\text { priorizar } \\
\text { necessidade }\end{array}$ & $\operatorname{sim}$ & $\begin{array}{l}\text { As necessidades são priorizadas quando representam forte ameaça ao } \\
\text { funcionamento da instituição. Por exemplo, à época das entrevistas, } \\
\text { eram priorizadas a reforma do telhado (que apresentava goteiras, } \\
\text { principalmente nas oficinas e nos dormitórios) e a compra de móveis } \\
\text { como camas e carteiras escolares, por haverem atingido nível crítico } \\
\text { de funcionalidade. A reposição das portas dos banheiros (retiradas } \\
\text { após apodrecerem) e o conserto das janelas dos mesmos não são } \\
\text { prioridades no momento, embora representem claras necessidades da } \\
\text { instituição. }\end{array}$ \\
\hline $\begin{array}{l}\text { divulgar } \\
\text { publicamente } \\
\text { necessidade } \\
\text { priorizada } \\
\text { montar equipe } \\
\text { para planejamento } \\
\text { de arrecadação de } \\
\text { recursos }\end{array}$ & NAO & $\begin{array}{l}\text { Não existem pessoas dedicadas à atividade de marketing. A marca } \\
\text { "Pão dos Pobres" é conhecida pela sua história, mas esforços } \\
\text { específicos para a divulgação das suas atividades e necessidades ainda } \\
\text { são incipientes. } \\
\text { A formação de equipes para arrecadação de recursos acontece, mas } \\
\text { tende a ser emergencial. Este fato é amparado pela carência de } \\
\text { recursos humanos e de planejamento de mais longo prazo, de modo } \\
\text { que não se consegue reunir, muitas vezes, as pessoas mais adequadas } \\
\text { para casos específicos. }\end{array}$ \\
\hline $\begin{array}{l}\text { determinar tarefas } \\
\text { específicas para } \\
\text { se atacar } \\
\text { necessidade } \\
\text { priorizada }\end{array}$ & $\operatorname{sim}$ & $\begin{array}{l}\text { A determinação de tarefas é realizada, mas, dada a urgência para o } \\
\text { enfrentamento das necessidades, pode ocorrer de não se conseguir } \\
\text { estabelecer um conjunto ótimo de tarefas a serem implementadas. }\end{array}$ \\
\hline $\begin{array}{l}\text { selecionar equipe } \\
\text { de implementação }\end{array}$ & sim & $\begin{array}{l}\text { Equipes são formadas, mas, dada a urgência para o enfrentamento das } \\
\text { necessidades, pode ocorrer de não se conseguir reunir o pessoal mais } \\
\text { habilitado. Além disso, a escassez de recursos humanos e o fato de } \\
\text { muitos serem voluntários dificultam a composição de uma equipe mais } \\
\text { especializada. }\end{array}$ \\
\hline
\end{tabular}

Quadro 1.1. Comparação entre modelo conceitual e situação problemática expressada (relatos de agosto de 1999). 
Carlo Gabriel Porto Bellini - Ionara Rech - Denis Borenstein

\begin{tabular}{|c|c|c|}
\hline $\begin{array}{c}\text { MODELO } \\
\text { CONCEITUAL }\end{array}$ & $\begin{array}{l}\text { M UNDO } \\
\text { REAL }\end{array}$ & COMENTÁRIOS \\
\hline $\begin{array}{l}\text { associar-se a } \\
\text { outras pessoas e } \\
\text { organizações }\end{array}$ & $\operatorname{sim}$ & $\begin{array}{l}\text { A instituição busca, constantemente, parcerias com outras pessoas e } \\
\text { organizações, de modo a captar recursos para a entidade. Isto é feito } \\
\text { via contato telefônico, visita pessoal, etc. A força de argumentação, no } \\
\text { entanto, fica prejudicada pelo fato de não haver uma campanha formal } \\
\text { divulgada. }\end{array}$ \\
\hline $\begin{array}{l}\text { providenciar } \\
\text { condições para } \\
\text { implementação }\end{array}$ & $\operatorname{sim}$ & $\begin{array}{l}\text { Esta tarefa é realizada, mas, dada a urgência para o enfrentamento das } \\
\text { necessidades, pode ocorrer de não se conseguir determinar um } \\
\text { conjunto ótimo de condições para implementação de atividades. Falta } \\
\text { previsão de possíveis necessidades futuras. }\end{array}$ \\
\hline $\begin{array}{l}\text { distribuir tarefas } \\
\text { para a equipe }\end{array}$ & $\operatorname{sim}$ & $\begin{array}{l}\text { As tarefas são distribuídas, mas não de uma forma planejada, em } \\
\text { função, provavelmente, do nível de urgência para o enfrentamento das } \\
\text { necessidades. Designam-se pessoas que estiverem mais disponíveis, e } \\
\text { não as mais habilitadas para a tarefa particular. }\end{array}$ \\
\hline $\begin{array}{l}\text { listar possíveis } \\
\text { alternativas de } \\
\text { ação individual }\end{array}$ & NÃO & $\begin{array}{l}\text { Pelo caráter de urgência ou por limitações individuais, as pessoas } \\
\text { envolvidas reduzem sensivelmente o levantamento e a análise de } \\
\text { possíveis alternativas de implementação de suas tarefas particulares. }\end{array}$ \\
\hline $\begin{array}{l}\text { escolher a melhor } \\
\text { alternativa } \\
\text { individual }\end{array}$ & NÄO & $\begin{array}{l}\text { A alternativa escolhida é, na maior parte das vezes, a que primeiro } \\
\text { surgiu ou a que se apresentava como mais passível de realização. }\end{array}$ \\
\hline $\begin{array}{l}\text { implementar } \\
\text { alternativa } \\
\text { escolhida }\end{array}$ & $\operatorname{sim}$ & $\begin{array}{l}\text { Uma ação é mplementada, mas, conforme já comentado, pode não } \\
\text { representar a melhor alternativa, caso outras tivessem sido avaliadas. }\end{array}$ \\
\hline $\begin{array}{l}\text { avaliar resultados } \\
\text { individuais }\end{array}$ & NÃO & $\begin{array}{l}\text { As pessoas envolvidas na campanha de arrecadação de recursos não } \\
\text { são avaliadas individualmente pelos resultados obtidos das tarefas a } \\
\text { elas designadas. }\end{array}$ \\
\hline $\begin{array}{l}\text { avaliar resultado } \\
\text { geral }\end{array}$ & $\operatorname{sim}$ & $\begin{array}{l}\text { Existe uma avaliação geral de resultados, ainda que não muito } \\
\text { profunda - devido à inexistência de um planejamento mais rigoroso } \\
\text { para arrecadação de recursos. }\end{array}$ \\
\hline
\end{tabular}

\section{Quadro 1.2. Comparação entre modelo conceitual e situação problemática expressada (relatos de agosto de 1999).}

A partir das comparações entre o modelo conceitual e a realidade, alterações possíveis e desejáveis foram sugeridas (Quadro 2), para que o processo de planejamento e desenvolvimento eficientes de um programa de arrecadação de recursos seja efetivo na instituição. As sugestões dizem respeito sobretudo à identificação e monitoramento de necessidades, desenvolvimento de programas específicos de marketing para cada campanha e manutenção de um número mínimo de pessoas com boas relações na sociedade, para facilitarem as associações necessárias com outras pessoas e organizações. Além disso, sugere-se disponibilizar tempo para que cada pessoa organize suas tarefas e avalie o seu desempenho nas tarefas recebidas.

Ao final dos trabalhos, o conjunto de sugestões passou a ser propriedade do Pão dos Pobres, que dele dispôs conforme seu interesse. 


\section{SUGESTÖES}

Formalizar um procedimento para identificação e prevenção periódicas de necessidades da instituição. Tal procedimento pode contar com uma pessoa ou um grupo específico para isto.

Desenvolver um consistente programa de marketing para impulsionar campanhas priorizadas de arrecadação de recursos, que se valha da marca "Pão dos Pobres" como mais uma forma de sensibilização da comunidade. Possivelmente, um programa desse tipo deverá ser efetivado mediante a contratação de empresa especializada.

Tentar manter um número mínimo de pessoas dispostas a participarem de planejamento e desenvolvimento de campanhas de arrecadação de recursos. Preferencialmente, pessoas com bons contatos pessoais e profissionais na sociedade, de modo a poderem melhor agilizar associações que se façam interessantes em situações específicas.

Mantendo-se um número mínimo de pessoas envolvidas no planejamento de campanhas de arrecadação de recursos, reservar um tempo maior para a identificação precisa de tarefas necessárias para o bom andamento dos trabalhos.

Estabelecer programas de estágio de universitários de diversas áreas na instituição, de modo a que ela conte com mão-de-obra qualificada e com maior flexibilidade de horários.

Fazer uso do programa de marketing sugerido anteriormente como forte argumento para estabelecerem-se parcerias com outras organizações e pessoas.

Com a possibilidade de serem previstas necessidades futuras, providenciar ou identificar antecipadamente os meios para a viabilização das tarefas envolvidas.

Disponibilizar, para cada indivíduo da equipe de arrecadação de recursos, tempo para que identifique alternativas de implementação das tarefas distribuídas.

Disponibilizar, para cada indivíduo da equipe de arrecadação de recursos, tempo para que avalie os resultados de suas atividades. Além disso, informar a todos os participantes das campanhas sobre a obrigatoriedade da avaliação, a ser reportada por escrito para a equipe de planejamento e para a coordenação dos trabalhos.

\section{Quadro 2. Sugestões para implementação.}

\section{CONSIDERAÇÕES FINAIS}

Este artigo descreveu uma aplicação da Soft Systems Methodology (SSM), com o objetivo de divulgar no contexto brasileiro a SSM como metodologia para o tratamento de questões sociais complexas. Adicionalmente, por meio de uma aplicação prática e rigorosa da metodologia em caso real de organização filantrópica, buscou-se conduzir um diagnóstico sistêmico que ajudasse a organização a promover ações de melhoria gerencial. Por fim, quis-se incentivar a interação de acadêmicos e empresários com setores comunitários especialmente necessitados.

Desenvolvida no início dos anos 1980 por Peter Checkland e consolidada na literatura (Ranyard, 2000; Rose, 1997), a SSM tem sido explorada em uma variedade de campos de pesquisa, bem como serve a interesses práticos igualmente diversos. Entretanto, o contexto nacional ainda carece de aplicações consistentes da metodologia, bem como está longe de possuir um histórico de trabalhos que possam fundamentar ponderações acerca da SSM no Brasil. O artigo presente constitui iniciativa em direção à construção de uma tal base de experiências.

O ambiente para aplicação da SSM foi pensado de modo a se oferecer, gratuitamente, benefícios a alguma organização filantrópica; em contrapartida, os autores poderiam conhecer procedimentos 
administrativos e operacionais da entidade escolhida, enriquecendo as suas experiências profissionais. Assim, elegeutse para estudo - por critérios de complexidade de investigação, facilidade de acesso e importância comunitária - a organização filantrópica porto-alegrense Pão dos Pobres de Santo Antônio, que presta assistência a meninos carentes há mais de cem anos.

O benefício revertido para a entidade com a aplicação da SSM basicamente se refere à auto-avaliação sistêmica promovida. Em especial, funcionários e voluntários participantes das entrevistas, ao descreverem os seus departamentos e a entidade como um todo, puderam pensar a respeito do contexto em que estão inseridos, estruturando as suas atividades diárias e propondo sugestões de melhoria para problemas identificados. A SSM também se mostrou importante para reunir e organizar visões muitas vezes divergentes a respeito de uma realidade complexa comum. Foi, ainda, apropriada para estimular o debate acerca de possíveis alternativas para essa realidade particular, debate do qual todos os participantes saíram com significativo aprendizado. Ressalta-se, porém, que a implementação das alternativas para tratamento da situação problemática originalmente identificada não pertence ao escopo de aplicação da SSM (Ranyard, 2000), não sendo, assim, reportada neste trabalho.

A partir do diagnóstico da organização, ações foram priorizadas no sentido de se desenvolver um programa de arrecadação de recursos financeiros, materiais e de pessoal para a manutenção da mesma em termos de estrutura física e necessidades específicas dos meninos internos. No programa sugerido, verificou-se que alguns de seus componentes já são realidade no Pão dos Pobres, embora alguns precariamente; outros, contudo, devem ser implementados desde o início, pois problemas operacionais e de percepção bloquearam a sua efetividade até o momento.

Devido a impedimentos relacionados ao período de férias em que se encontrava a instituição à época do estudo, não se realizaram discussões em grupo com os envolvidos na situação problemática - e esta constitui a sua principal limitação; em vez disso, conduziram-se entrevistas individuais. Embora contrário a uma aplicação "pura" da SSM, este procedimento não é estranho a práticas reportadas em outros trabalhos de relevância acadêmica (veja-se a discussão de um caso em Gregory e Lau, 1999, Kidd e Leung, 2000, Gregory, 2000 e Kidd, 2000), bem como a validação dos resultados pela entidade sugere o acerto das escolhas metodológicas efetuadas durante a aplicação ora descrita. Também se indica como limitação do estudo a impossibilidade de se haver acompanhado o Pão dos Pobres em seu ritmo normal de atividades, em função do já mencionado período de férias.

No que diz respeito a benefícios percebidos pelos autores com a aplicação, destaca-se a satisfação de haverem conhecido melhor o trabalho de pessoas dedicadas ao serviço comunitário. Também a aproximação a realidades perturbadoras - como a complexa rede social em que se inserem os meninos carentes - foi positiva e impulsionou a idéia de que o trabalho deveria produzir resultados concretos. Um terceiro aspecto que estimulou os autores foi o fato de o Pão dos Pobres ser uma organização bastante segmentada em atividades distintas e relacionadas, oferecendo, assim, riqueza de questões tratáveis sob a ótica administrativa.

Como sugestões para estudos futuros, identifica-se como prioritária a caracterização da realidade do Pão dos Pobres hoje, para que se possa compará-la com aquela sobre a qual os autores trabalharam. Fundamentalmente, interessa saber quais efeitos o estudo realizado teve nas atividades de arrecadação de recursos para o Pão dos Pobres, no caso de este ter adotado a proposta aqui descrita. Também se visualiza a possibilidade de, em o presente esforço havendo sido positivo para a instituição, proceder-se ao estudo de outros sistemas relevantes (identificados neste trabalho ou em um próximo, mais atual). Por fim, sugere-se que outros meios de modelagem de situações complexas sejam empregados na entidade - em especial, nos mesmos sistemas aqui discutidos - e que se comparem os resultados com 
os da presente aplicação da SSM ${ }^{\mathrm{i}}$.

\section{Artigo recebido em 27.01.2003. Aprovado em 08.10.2003}

\section{REFERÊNCIAS}

ATKINSON, C. J. The 'soft information systems and technologies methodology' (SISTeM): an actor network contingency approach to in tegrated development. European Journal of Information Systems, v. 9, n. 2. 2000, pp. 104-123.

BINYUSOFF, M., JENKINS, J. An approach to development of decision-support systems for a publicsector administration. Journal of Information Technology, v. 9, n. 1. 1994, pp. 29-37.

CHECKLAND, P. Systems thinking, systems practice. Chichester: John Wiley \& Sons, 1981.

CHECKLAND, P. From optimizing to learning: a development of systems thinking for the 1990s. Journal of the Operational Research Society, v. 36, n. 9. 1985a, pp. 757-767.

CHECKLAND, P. Achieving 'desirable and feasible' change: an application of soft systems methodology. Journal of the Operational Research Society, v. 36, n. 9. 1985b, pp. 821-831.

CHECKLAND, P. Systems thinking. In: CURRIE, W. L., GALLIERS, B. (Eds.). Rethinking management information systems: an interdisciplinary perspective. New York: Oxford University Press, 1999, pp. 45-56.

CLARKE, S., LEHANEY, B. Mixing methodologies for information systems development and strategy: a higher education case study. Journal of the Operational Research Society, v. 51, n. 5. 2000, pp. 542-556.

COYLE, R. G., ALEXANDER, M. D. W. Two approaches to qualitative modelling of a nation's drugs trade. System Dynamics Review, v. 13, n. 3. 1997, pp. 205-222.

DIMAGGIO, P. J., POWELL, W. W. The iron cage revisited: institutional isomorphism and collective rationality in organizational fields. American Sociological Review, v. 48. 1983, pp. 147-160.

FLOOD, R. L., CARSON, E. R. Dealing with complexity: an introduction to the theory and application of systems science. New York: Plenum Press, 1988.

GREGORY, F. H. A reply to Kidd and Leung. Journal of the Operational Research Society, v. 51, n. 5. 2000, pp. 642-644.

GREGORY, F. H., LAU, S. P. Logical soft systems modelling for information source analysis - the case of Hongkong Telecom. Journal of the Operational Research Society, v. 50, n. 2. 1999, pp. 124137.

JACKSON, M. C. Towards coherent pluralism in management science. Journal of the Operational 
Research Society, v. 50, n. 1. 1999, pp. 12-22.

KIDD, J. B. A reply from Kidd (Leung, in absentia). Journal of the Operational Research Society, v. 51, n. 5. 2000, pp. 644-646.

KIDD, J. B., LEUNG, J. A note with respect to Gregory and Lau's paper 'logical soft systems modelling for information source analysis - the case of Hong Kong Telecom'. Journal of the Operational Research Society, v. 51, n. 5. 2000, p. 642.

MINGERS, J. The contribution of critical realism as an underpinning philosophy for OR/MS and systems. Journal of the Operational Research Society, v. 51, n. 11. 2000, pp. 1256-1270.

O'SHAUGHNESSY, N. Social propaganda and social marketing: a critical difference? European Journal of Marketing, v. 30, n. 10/11. 1996, pp. 54-67.

PATCHING, D. Seeking out the issues: how soft systems methodology was employed to advise a social services department on the use of information technology. OR Insight, v. 5, n. 1. 1992, pp. 9-14.

PIDD, M. Modelagem empresarial: ferramentas para tomada de decisão. Tradução: Gustavo Severo de Borba et al. Porto Alegre: Artes Médicas, 1998.

REID, J. I., GRAY, D. I., KELLY, T. C., KEMP, E. A. An application of SSM in the on-farm labour situation in the New Zealand dairy industry. Systems Research and Behavioral Science, v. 16, n. 4. 1999, pp. 341-350.

RANYARD, J. C. Commentary on Checkland (1985): achieving 'desirable and feasible' change: an application of soft systems methodology. Journal of the Operational Research Society, v. 51, n. 1. 2000, pp. 1347-1348.

ROSE, J. Soft systems methodology as a social science research tool. Systems Research and Behavioral Science, v. 14, n. 4. 1997, pp. 249-258.

ROSE, J. Information systems development as action research - soft systems methodology and structuration theory. PhD thesis. Management School, Lancaster University, 2000.

ROSE, J. Interaction, transformation and information systems development - an extended application of Soft Systems Methodology. Information Technology \& People, v. 15, n. 3. 2002, pp. 242-268.

WHEELER, F. P. Soft systems methodology in action: including a 30-year retrospective. Journal of the Operational Research Society, v. 51, n. 5. 2000, pp. 648-649.

WILLIAMS, T., DICKSON, K. Teaching real-life OR to MSc students. Journal of the Operational Research Society, v. 51, n. 12. 2000, pp. 1440-1448.

\footnotetext{
i Os autores destacam a importância de contribuições dos revisores anônimos da RAE e de Rita de Cássia de Faria Pereira para a qualidade do artigo. Agradecem, em especial, a todas as pessoas do Pão dos Pobres que gentilmente participaram do estudo.
} 


\section{Carlo Gabriel Porto Bellini}

Professor-assistente do Centro de Ciências Exatas e Tecnológicas da Universidade do Vale do Rio dos Sinos. Doutorando em Administração pela Universidade Federal do Rio Grande do Sul. Mestre em Administração e bacharel em Ciência da Computação pela UFRGS.

E-mail: cgpbellini@ea.ufrgs.br

Endereço: Av. Ipiranga, 3377/901, Porto Alegre - RS, 90610-001

Interesses de Pesquisa: desenvolvimento de software personalizado, comunidades mediadas pela Internet, gestão da informação, sistemas de informações gerenciais, métodos de pesquisa.

\section{Ionara Rech}

Professora-assistente da FACE/PUCRS e da Faculdade Cenecista Nossa Senhora dos Anjos (FACENSA). Mestre e bacharel em Administração pela UFRGS.

E-mail: ionara@pucrs.br

Endereço: R. Gen. Bento Martins, 702/601, Porto Alegre - RS, 90010-080

Interesses de pesquisa: sistemas de informações, impacto da tecmologia da informação nas organizações, sistemas de informações para a gestão de produção e operações, métodos de pesquisa.

\section{Denis Borenstein}

Professor-adjunto da Escola de Administração da Universidade Federal do Rio Grande do Sul. Mestre em Administração pela UFRGS e PhD em Pesquisa Operacional pela University of Strathclyde. Engenheiro Naval pela UFRJ.

E-mail: denisb@ea.ufrgs.br

Endereço: R. Washington Luiz, 855/318, Porto Alegre - RS, 90010-460

Interesses de pesquisa: modelagem de sistemas, simulação de sistemas, avaliação sistêmica de organizações. 